\title{
The Proteinase-Activated Receptor 2 Is Involved in Nociception
}

\author{
W. A. Hoogerwerf, ${ }^{1}$ L. Zou, ${ }^{2}$ M. Shenoy, ${ }^{1}$ D. Sun, ${ }^{1}$ M. A. Micci, ${ }^{1}$ H. Lee-Hellmich, ${ }^{1}$ S. Y. Xiao, ${ }^{2}$ J. H. Winston, ${ }^{1}$ \\ and P. J. Pasricha ${ }^{1}$ \\ ${ }^{1}$ Enteric Neuromuscular Disorders and Pain Laboratory, Division of Gastroenterology and Hepatology, and ${ }^{2}$ Department \\ of Pathology, University of Texas Medical Branch, Galveston, Texas 77555-0764
}

The proteinase-activated receptor 2 is expressed on a subset of primary afferent neurons and may participate in the neurogenic component of inflammation. We hypothesized that this receptor may also play a role in neuronal sensitization and contribute to the pathogenesis of pain in inflammatory conditions such as pancreatitis. Using a specific proteinase-activated receptor 2 activating peptide, we found evidence of such sensitization in vitro in the form of enhanced capsaicin- and $\mathrm{KCl}$-evoked release of calcitonin gene-related peptide, a marker for nociceptive signaling. We then demonstrated that injection of the proteinase-activated receptor 2 activating peptide into the pancreatic duct can activate and sensitize pancreas-specific afferent neurons in vivo, as measured by Fos expression in the dorsal horn of the spinal cord. These observations suggest that proteinase-activated receptor 2 contributes to nociceptive signaling and may provide a novel link between inflammation and pain.

Key words: proteinase-activated receptor 2; dorsal root ganglia; nociception; pancreas; Fos; neuronal sensitization
The proteinase-activated receptors (PARs) are a family of four G-protein-coupled receptors (Vu et al., 1991; Nystedt et al., 1994, 1995; Ishihara et al., 1997; Kahn et al., 1998; Xu et al., 1998) that share a unique mechanism of activation. Serine proteases such as trypsin and thrombin cleave PARs, unmasking the "tethered ligand," an extracellular N-terminal domain that subsequently binds and activates the receptor. Synthetic activating peptides that correspond to the tethered ligands of the various PARs can also activate their individual receptor directly (Hollenberg et al., 1997; Al-Ani et al., 1999). Activation of PARs has been studied most extensively in relation to platelet activation, although studies have also suggested a possible role in inflammation (Nystedt et al., 1996). Recently, proteinase-activated receptor-2 (PAR-2) expression was detected on a subset of peripheral peptidergic neurons and was shown to be involved in the neurogenic component of inflammation (Steinhoff et al., 2000). Kawabata et al. (2001) showed that peripheral PAR-2 activation, by intraplantar injection of the PAR-2 activating peptide (AcPep), can produce thermal but not mechanical hyperalgesia in the rat. Most recently, Vergnolle et al. (2001) showed that intraplantar administration of a more potent and longer-acting form of AcPep reduced rat paw withdrawal latency by 64 and $47 \%$ after 4 and $24 \mathrm{hr}$, respectively. Similar observations were made in wild-type but not in PAR-2deficient mice, suggesting a direct role for PAR-2 in pain transmission. We hypothesized that a PAR-2-mediated mechanism may lead to neuronal sensitization and hence contribute to the pathogenesis of pain in the pancreas, an organ in which inflammation results in activation of endogenous proteases such as

Received March 26, 2001; revised Aug. 29, 2001; accepted Aug. 31, 2001.

This work was supported in part by an American Digestive Health Foundation faculty transition award (W.A.H.). We thank Dr. W. D. Willis and Dr. S. E. Crowe for their critical review of this manuscript. We thank Brenda Kenworthy for excellent technical assistance.

Correspondence should be addressed to Dr. Pankaj Jay Pasricha, Division of Gastroenterology and Hepatology, University of Texas Medical Branch, 4.106 McCullough Building, 301 University Boulevard, Galveston, TX 77555-0764. E-mail: jpasrich@utmb.edu.

Copyright (C) 2001 Society for Neuroscience $\quad 0270-6474 / 01 / 219036-07 \$ 15.00 / 0$ trypsin, a potent activator of PAR-2. The results of our experiments suggest that PAR-2 activation can sensitize adult rat dorsal root ganglion (DRG) neurons in vitro. Furthermore, activation of PAR-2 within the pancreas can also sensitize this organ to noxious stimulation in vivo. These findings suggest a potentially important role for PAR-2 and proteases in pancreatic nociception.

\section{MATERIALS AND METHODS}

Animals. Adult male Sprague Dawley rats (Harlan Sprague Dawley, Cumberland, IN), 200-250 gm, were used in all experiments. Experimental protocols involving animals were approved by our Institutional Animal Care and Use Committee in accordance with the guidelines provided by the National Institutes of Health.

Reverse transcription-PCR. Total RNA was isolated from the DRGs of normal male Sprague Dawley rats, using the Ultraspec RNA isolation system (Biotex Laboratories Inc., Houston, TX) and was treated with DNase I. Reverse transcription (RT)-PCR (ProSTAR Ultra HF RTPCR System; Stratagene, La Jolla, CA) was performed using PAR-2specific primers (5'-TCA GTA GGA GGT TTT AAC AC-3' and 5'ATG CGA AGT CTC AGC CTG GC- $3^{\prime}$ ) as follows: initial denaturation $95^{\circ} \mathrm{C}$ for $1 \mathrm{~min}(1 \mathrm{cycle}), 95^{\circ} \mathrm{C}$ for $1 \mathrm{~min}, 56^{\circ} \mathrm{C}$ for $1 \mathrm{~min}, 68^{\circ} \mathrm{C}$ for $15 \mathrm{~min}$, and $68^{\circ} \mathrm{C}$ final extension for $10 \mathrm{~min}$. The fragments were purified from a low-melt agarose gel and were ligated into a plasmid vector, pGEM $5 \mathrm{Z}(\mathrm{f})+$ (Promega, Madison, WI). The identity of the PCR product was confirmed by sequence analysis using an automated Applied Biosystems Inc. (Foster City, CA) sequencer.

Immunohistochemistry. Primary neuronal cultures were fixed in $100 \%$ methanol for $10 \mathrm{~min}$ at $-20^{\circ} \mathrm{C}$ and incubated for 20 min with PBS containing $0.3 \%$ Triton X-100 and 5\% normal donkey serum. Slides were incubated overnight at $4^{\circ} \mathrm{C}$ with a goat polyclonal antibody raised against the $\mathrm{N}$ terminus of the PAR-2 receptor at a dilution of 1:200 (Santa Cruz Biotechnology, Santa Cruz, CA) in PBS containing 5\% normal donkey serum. Slides were rinsed in PBS at room temperature and incubated with donkey-anti-goat antiserum (Alexa 594; Molecular Probes, Leiden, The Netherlands) at a dilution of 1:200 for $1 \mathrm{hr}$ at room temperature. Slides were washed in PBS, rinsed in $\mathrm{dH}_{2} \mathrm{O}$, and mounted with FluorSave (Calbiochem, La Jolla, CA). Controls for specificity of immunolabeling included omission of the primary antibody from the immunostaining procedure. Serial, confocal optical sections of a z-series were obtained with a video-rate confocal laser scanning microscope (Noran Instruments, Madison, WI) coupled to a Nikon (Tokyo, Japan) Diaphot inverted microscope. 
Cell culture. Primary cultures of rat DRG neurons were prepared from male adult Sprague Dawley rats as described by Delree et al. (1989). After enzymatic treatment and dissociation, neurons were spun through a Percoll cushion and were plated at a density of 10,000-20,000 neurons per well on a 48 -well tissue culture plate. Cultures were maintained in DMEM plus $10 \%$ fetal bovine serum (FBS) supplemented with penicillin-streptomycin, $150 \mu \mathrm{M}$ uridine, $50 \mu \mathrm{M}$ 5-fluro-2-deoxyuridine, and 50 $\mathrm{ng} / \mathrm{ml}$ nerve growth factor (NGF) (murine, recombinant, 2.5S; Promega) for $5 \mathrm{~d}$ before release experiments were performed.

Peptides. AcPep (SLIGRL) and control peptide (CoPep) (RLGILS) were prepared by standard solid-phase synthesis procedures by the University of Texas Medical Branch Core Protein Facility.

Calcitonin gene-related peptide release assay. Immunoreactive (IR) calcitonin gene-related peptide (CGRP) release from DRG cultures was performed as described by Hingtgen et al. (1995). Briefly, DRG cultures were washed with release buffer (RB) (25 mM HEPES, pH 7.4, $135 \mathrm{~mm}$ $\mathrm{NaCl}, 3.5 \mathrm{~mm} \mathrm{KCl}, 2.5 \mathrm{~mm} \mathrm{CaCl}_{2}, 1 \mathrm{~mm} \mathrm{MgCl}_{2}, 3.3 \mathrm{~mm}$ glucose, $0.1 \%$ BSA, and $1 \mu \mathrm{M}$ phosphoamnidon) and were incubated for $10 \mathrm{~min}$ at $37^{\circ} \mathrm{C}$ in RB plus $0.1 \%$ ethanol (capsaicin-vehicle) to measure basal CGRP release. Fresh RB containing the appropriate concentration of AcPep or CoPep was added for an additional 10 min. Peptide treatment was followed by a $10 \mathrm{~min}$ incubation with an appropriate dose of capsaicin or $\mathrm{KCl}$. CGRP quantification was performed as described by Winston et al. (2001).

Intraductal (pancreatic duct) injection. To administer the necessary peptides directly into the rat pancreatic duct, we followed a modified protocol, previously described by Kim et al. (1996). Briefly, rats were anesthetized with sodium nembutal (Abbott Laboratories, Chicago, IL) ( $50 \mathrm{mg} / \mathrm{kg}$ body weight, i.p.). The peritoneum was incised to expose the duodenum, and the duodenal loop was pulled out. The pancreatic duct entering the duodenum was identified under dissecting microscope, and a small niche was made into the duct with a 30 gauge needle. A polyethelene 10 tubing $(0.61 \mathrm{~mm}$ outer diameter) (Becton Dickinson, Franklin Lakes, NJ) was guided into the duct and tied to secure its position. The position of the tube in the pancreatic duct was confirmed by observing bile flowing through the tubing. The common bile duct was ligated close to the liver to prevent entry of the injected substance into the liver. Similarly, the duct was ligated near its entry into the duodenum. Five hundred microliters per rat of $100 \mu \mathrm{M}$ AcPep or CoPep was injected through a syringe connected to the tubing. Thirty minutes later, $0.1,0.3$, 0.5 or $0.7 \mathrm{mg} / \mathrm{kg}$ capsaicin (total volume $500 \mu \mathrm{l}$ ) or vehicle (1× PBS, $10 \%$ $\mathrm{ETOH}$, and $1 \%$ Tween 20 ) was injected. Three rats were included in each treatment group in each experiment, and the experiments were repeated on three separate occasions. The tubing was carefully removed, and bile flow from the liver into the duodenum was reestablished. The abdominal cavity was closed with sutures. Rats were killed $2.5 \mathrm{hr}$ after the initial injection.

Fos staining. Rats were anesthetized with sodium pentobarbital (50 $\mathrm{mg} / \mathrm{kg}$, i.p.) and perfused with $200 \mathrm{ml}$ PBS followed by $500 \mathrm{ml}$ ice-cold freshly prepared $4 \%$ paraformaldehyde in PBS. Segments T9 and T10 were identified as follows: DRG T13 were identified by their location adjacent to the last rib (Hebel, 1976). Counting down from DRG T13, DRG T10 and T9 were identified. The dorsal roots from ganglia T10 and T9 enter the spinal cord in the middle of spinal cord segments T10 and $\mathrm{T}$, respectively. The spinal cord was marked by a longitudinal cut to allow for left or right side identification during Fos counting and then removed, post-fixed in $4 \%$ paraformaldehyde for $18 \mathrm{hr}$ at $4^{\circ} \mathrm{C}$, and placed in PBS, pH 7.4, containing 30\% sucrose for $24 \mathrm{hr}$ at $4^{\circ} \mathrm{C}$. Segments receiving input from the pancreas (T9-T10) were studied; spinal segments T5 and T12 served as internal controls to ensure that the effects noted on c-Fos expression were specific to the pancreas. Frozen sections $(40 \mu \mathrm{m})$ were cut on a cryostat and stored as floating sections in PBS at $4^{\circ} \mathrm{C}$. Every third section was stained for Fos with a rabbit polyclonal serum, 1:1000 dilution (Fos, Ab-5; Oncogene, Boston, MA), according to the manufacturer's protocol. Antibody staining was visualized using a biotinylated secondary antisera and Vectastain $\mathrm{ABC}$ peroxidase kit (Vector Laboratories, Burlingame, CA) with 3,3'-diaminobenzidine as substrate. Sections were mounted on Superfrost Plus slides (VWR Scientific, West Chester, PA) and dehydrated. The spinal cord was divided into three regions, $\mathrm{A}, \mathrm{B}$, and $\mathrm{C}$, respectively. The border between lamina II, the substantia gelatinosa, and lamina III was identified under darkfield optics. A line along this border was marked region A, which contained laminas I and II. Region B was identified by drawing an imaginary line between the ventral border of the dorsal horn and the superior border of the indentation by the intermediolateral nucleus

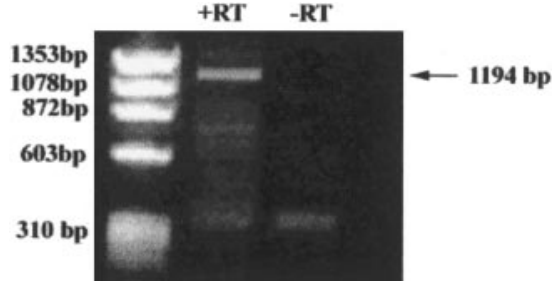

Figure 1. Amplification of a predicted 1199 bp fragment by RT-PCR from adult thoracic DRG RNA. A negative RT control showed no amplification.

(Molander et al., 1984). Region C was defined as the remainder of each hemisection (see Fig. 4). The number of Fos-IR neurons were counted in every third section per segment per region under bright-field illumination by an observer blinded to the different treatment groups and then averaged.

Pancreatic histology. Fresh specimens of rat pancreas were fixed in $10 \%$ formaldehyde (Sigma, St. Louis, MO) in PBS, pH 7.4, containing $1 \mathrm{~mm}$ $\mathrm{MgCl}_{2}$ at $4^{\circ} \mathrm{C}$ overnight. Sections from paraffin-embedded specimens were stained with hematoxyline and eosin and observed under a light microscope (BX60; Olympus Optical, Tokyo, Japan). Evaluation of the pathological changes on sections was based on the scales described by Tito et al. (1993). A pathologist blinded for the different treatment groups evaluated all sections.

Statistics. Release data are presented as the mean \pm SEM of wells pooled from three separate experiments. To compare the effects of activating peptide and control peptide on subsequent evoked release, an overall test based on the ANOVA was performed. If the test indicated that a difference existed, individual means were compared using the Bonferroni's multiple comparison test. Intraductal injection studies were analyzed using a two-way ANOVA, and individual means were compared using a Newman-Keuls multiple comparison test. Significance levels were set at $p<0.05$.

\section{RESULTS}

\section{PAR-2 is expressed in adult rat thoracic DRG neurons}

A previous report demonstrated PAR-2 expression in neurons from adult rat lumbar dorsal root ganglia (Steinhoff et al., 2000). We confirmed the presence of this receptor in adult rat thoracic DRG by amplifying the entire coding region of the PAR-2 gene by RT-PCR from total RNA, using PAR-2-specific primers (Fig. 1). PAR-2 immunoreactivity was also detected in cultured primary neurons using a PAR-2-specific antibody (Fig. 2). PAR-2 immunoreactivity was noted in the cytoplasm of the neuronal soma, as well as at the plasma membrane. Thus, PAR-2 is expressed in adult rat thoracic DRG neurons.

\section{The PAR-2 agonist activating peptide enhances capsaicin- and $\mathrm{KCl}$-evoked CGRP release in cultured DRG neurons}

To determine whether PAR-2 activation could enhance stimulusevoked release of CGRP, the effect of treatment with the PAR-2 AcPep $10 \mathrm{~min}$ before and throughout a $10 \mathrm{~min}$ incubation with $\mathrm{KCl}(70 \mathrm{~mm})$, vehicle only, or capsaicin (3, 10, 20, 50, and $100 \mathrm{~nm})$ was examined in cultured adult rat thoracic DRG neurons and compared with the effect of CoPep (Fig. 3). Treatment with AcPep $(10 \mu \mathrm{M})$ by itself for $10 \mathrm{~min}$ did not significantly increase CGRP release but produced a 1.5 -fold increase in $\mathrm{KCl}$-evoked CGRP release when compared with CoPep treatment $(2.7 \pm 0.1$ $\mathrm{ng} / \mathrm{ml}$ with AcPep vs $1.8 \pm 0.1 \mathrm{ng} / \mathrm{ml}$ with CoPep or $1.8 \pm 0.03$ ng $/ \mathrm{ml}$ without peptide; ${ }^{*} p<0.001$ ) (Fig. $3 A$ ). Treatment of rat thoracic DRG neurons with capsaicin evoked a concentrationdependent increase in CGRP release. The concentration-effect curve was bell-shaped with maximum CGRP release at $50 \mathrm{~nm}$ capsaicin. Pretreatment of DRG neurons with AcPep produced a 


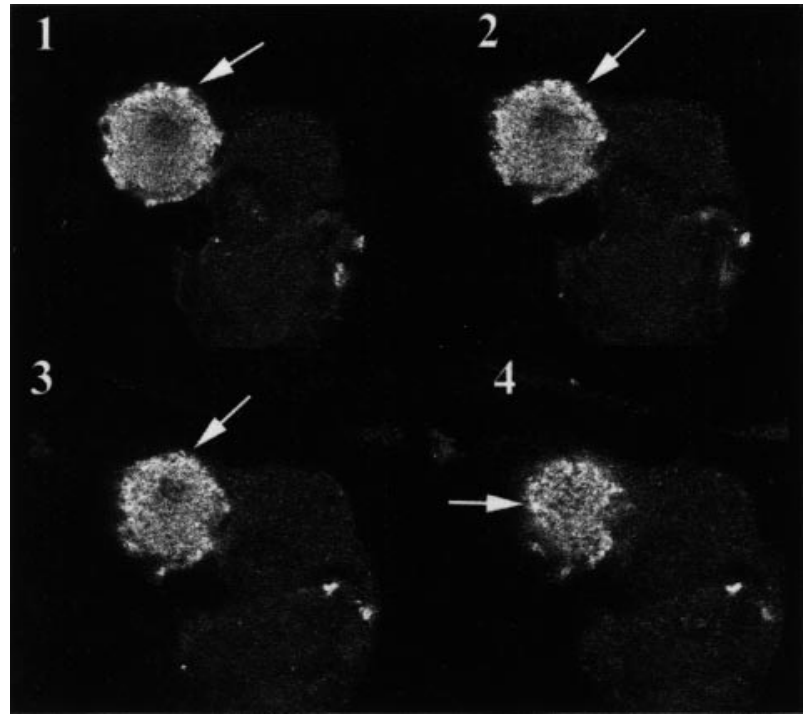

Figure 2. Serial, confocal optical sections of a $z$-series through a cultured PAR-2-IR DRG neuron. The slices show PAR-2-IR vesicles (arrows) right below the plasma membrane $(1,2$, arrows) and in the cytoplasm (3, $4)$. A large neuron is seen in the background. Sections were taken at $1 \mu \mathrm{m}$ intervals.
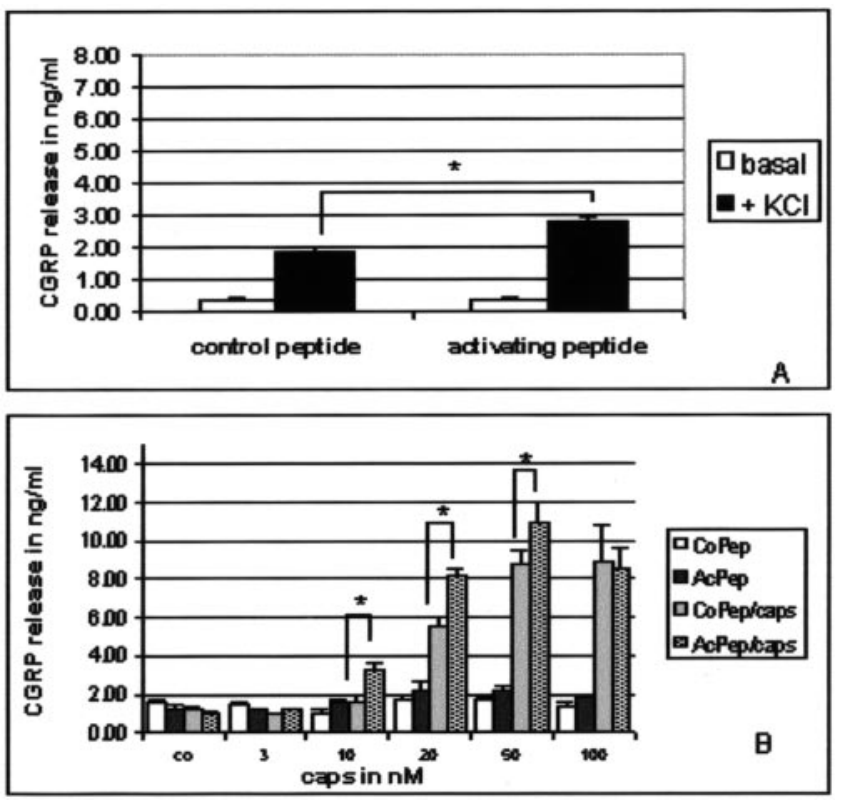

Figure 3. Histogram showing the amount of CGRP released from cultured adult rat thoracic DRG neurons during a 10 min pretreatment with either AcPep $(10 \mu \mathrm{M})$ or CoPep $(10 \mu \mathrm{M})$. Cultures were then treated with either $\mathrm{KCl}$ or varying concentrations of capsaicin (caps) for $10 \mathrm{~min}$ in the presence of AcPep or CoPep. Data are represented as the mean CGRP release of wells ( $\mathrm{KCl}$, total of 16 wells; capsaicin, total of four wells) from three separate experiments. $A$, Pretreatment with AcPep $(10 \mu \mathrm{M})$ increased CGRP release induced by $\mathrm{KCl}(70 \mathrm{~mm})\left({ }^{*} p<0.001\right)$. $B$, Pretreatment with AcPep $(10 \mu \mathrm{M})$ increased CGRP release induced by capsaicin 10, 20, and $50 \mathrm{~nm}\left({ }^{*} p<0.05\right)$.

significant increase in capsaicin-evoked CGRP release when compared with CoPep at 10, 20, and $50 \mathrm{~nm}(3.22 \pm 0.42,8.24 \pm 0.28$, and $11.00 \pm 1.04 \mathrm{ng} / \mathrm{ml}$ with AcPep vs $1.59 \pm 0.37,5.6 \pm 0.38$, and $8.8 \pm 0.7 \mathrm{ng} / \mathrm{ml}$ with CoPep, respectively; $p<0.05$ ) (Fig. $3 B$ ). This effect was most pronounced at $10 \mathrm{~nm}$ capsaicin, producing a

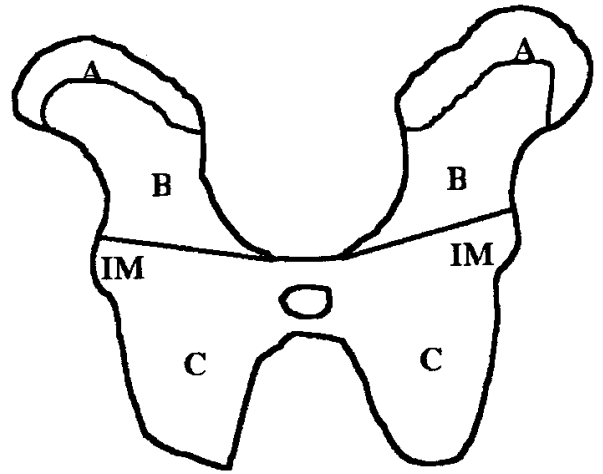

Figure 4. Drawing of a hemisection of the spinal cord showing specific regions that were analyzed for Fos immunoreactivity. The border between lamina II, the substantia gelatinosa, and lamina III was identified under dark-field optics. A line along this border marked region A, which contained laminas I and II. Region B was defined by a line between the ventral border of the dorsal horn and the superior border of the indentation by the intermediolateral (IM) nucleus (laminas III, IV, and V). Region C was defined as the remainder of each hemisection (laminas VII, VIII, IX, and X).

twofold increase with AcPep compared with CoPep. These results indicated that the PAR-2-specific agonist AcPep can sensitize the response of adult rat thoracic DRG neurons to excitatory stimuli in vitro.

\section{Activating peptide increases Fos expression in pancreatic spinal segments}

To evaluate the potential role of PAR-2 activation in nociception, the effect of intraductal pancreatic AcPep injections on both basal Fos expression and capsaicin-evoked Fos expression was studied in vivo (Fig. 5). Fos expression is a widely accepted indirect marker of neuronal activation in spinal nociceptive pathways (Hunt et al., 1987; Chapman and Besson, 1997). Immunohistochemical studies in combination with retrograde tracing in samples of DRGs have shown that the DRG afferent innervation of the rat pancreas arises from T5-L2 with maximum innervation at levels T8-T12 (Won et al., 1998). We focused our analysis on spinal segments T9 and T10 in which maximal Fos expression was observed previously after noxious pancreatic intraductal stimulation with capsaicin (our unpublished observations). There was no significant difference in Fos expression in any region between left and right hemisection (data not shown), and Fos data were therefore expressed as the sum of left and right hemisection. Maximum capsaicin-evoked Fos expression was present in region A (Fig. 4) and occurred in a concentration-dependent manner in region $\mathrm{A}$, reaching a plateau at capsaicin $0.5 \mathrm{mg} / \mathrm{kg}$. Inf usion of AcPep produced a statistically significant increase in capsaicinevoked Fos expression in region A (representing laminas I and II) when compared with CoPep at all capsaicin concentrations in segment T9 $(p<0.05)$, as well as all but one concentration of capsaicin $(0.7 \mathrm{mg} / \mathrm{kg})$ in segment T10 (Fig. 5A,B). Similar observations were made in regions $B$ and $C$. No significant differences in Fos expression were observed between treatment groups in segments T5 or T12, in keeping with our observation that these segments barely, if at all, receive input from the pancreas. Infusion of AcPep into the pancreatic duct followed by vehicle only produced more Fos-IR neurons in segments T9-T10 when compared with CoPep $(p<0.05)$ (Fig. $5 C)$.

To rule out the possibility that the Fos response was secondary to induction of inflammation in response to intraductal infusion 
A

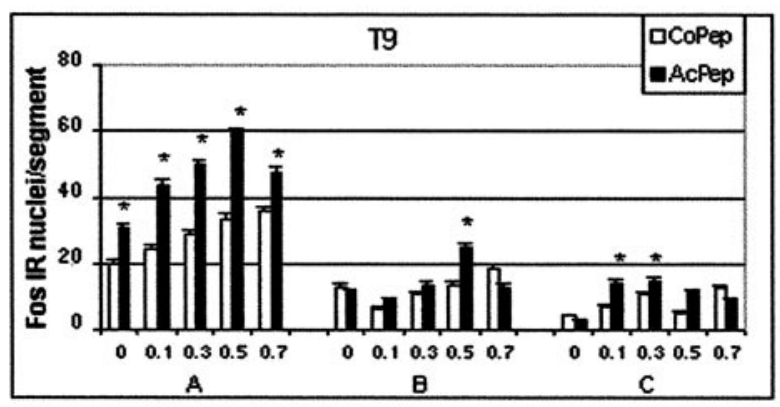

B

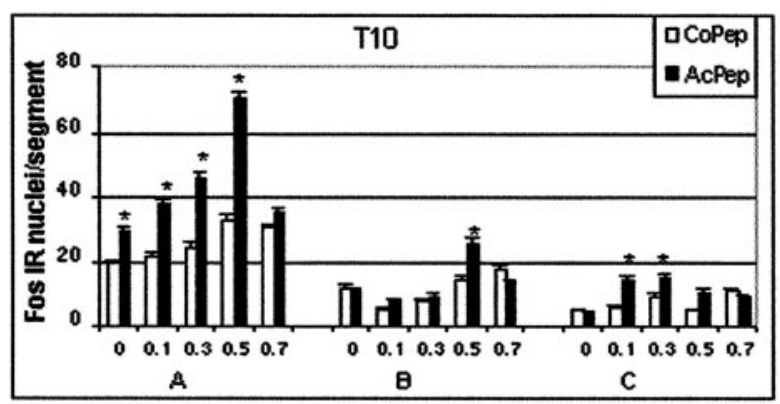

C

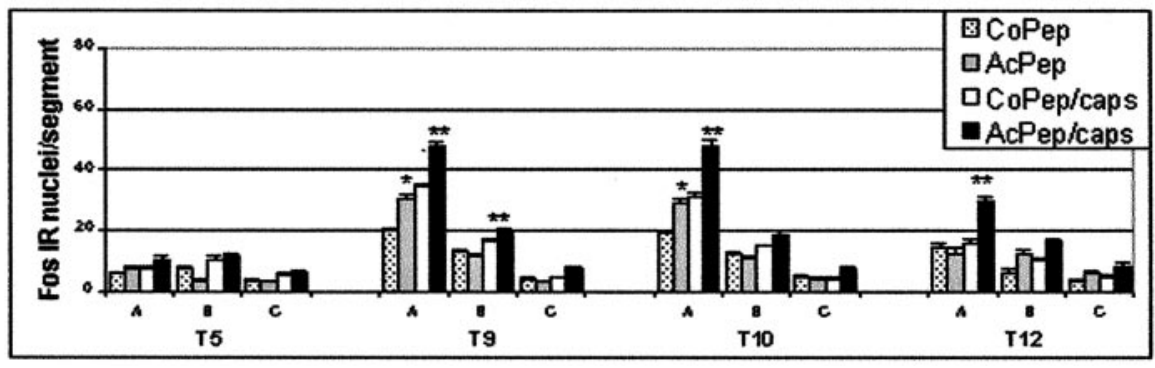

Figure 5. A, Histogram showing the distribution of Fos-IR nuclei over three different regions in rat spinal cord segment $\mathrm{T} 9$ after infusion of AcPep alone, CoPep alone, and different doses of capsaicin into the pancreatic duct. Results are expressed as number of Fos-IR neurons per segment \pm SE. Maximum Fos expression was noted in region $\mathrm{A}$. Infusion of $100 \mu \mathrm{M}$ AcPep alone into the pancreatic duct produced more Fos-IR neurons compared with CoPep or when followed by inf usion of capsaicin ( ${ }^{*} p<0.05$ vs CoPep). $B$, As above, for spinal segment T10. $C$, Histogram showing the distribution of Fos-IR nuclei over three different regions in the rat spinal cord segments T9-T10, T5, and T12 after infusion of 100 $\mu \mathrm{M}$ CoPep or AcPep, followed by $0.5 \mathrm{mg} / \mathrm{kg}$ capsaicin into the pancreatic duct. Maximal staining was found in segments $\mathrm{T} 9$ and $\mathrm{T} 10$.

of AcPep, pancreatic sections were evaluated using a histological scoring system developed by Tito et al. (1993). No evidence of pancreatitis was detected in any of the animals, and no histological differences were observed among the different treatment groups (overall inflammatory score for each group, $0.5 ; p$, not significant).

\section{DISCUSSION}

Inflammation and its sequelae are known to cause significant changes in the somatic sensory nervous system affecting peripheral nerves, spinal cord, and supraspinal structures. Several biological agents induced by inflammation, such as neurotrophins (e.g., NGF), prostanoids, bradykinin, and various cytokines, can sensitize peripheral nociceptors (Dray, 1995). This leads to an increase in afferent signaling, which in turn may cause sensitization at the central level, resulting in amplification and persistence of pain. Among the many potential sensitizing factors in this "inflammatory soup," little attention has been paid to the role of proteases. These enzymes are derived from humoral (thrombin and factor $\mathrm{Xa}$ ) and cellular (trypsin, tryptase, and other tryptic enzymes from mast cells) sources (Cocks and Moffat, 2000). In addition, inflammation in specific organs such as the pancreas may result in a significant release and activation of endogenous proteases (Hofbauer et al., 1998; Nguyen et al., 1999). We there- fore hypothesized that these activated proteases could have direct effects on sensory neurons, mediated by specific receptors such as PAR-2, shown previously to be present in sensory neurons (Steinhoff et al., 2000; Young et al., 2000). We confirmed these findings by demonstrating mRNA and protein expression in adult rat thoracic DRG, as well as a calcium response to AcPep and trypsin in cultured DRG neurons (our unpublished observations).

Stimulus-evoked neuropeptide release is a key measure of sensory neuron function and provides an index of neuronal sensitivity to various activating substances (Hingtgen et al., 1995). In this study, we show that adult DRG neurons can be sensitized in vitro by a specific PAR-2 agonist as measured by enhancement of stimulus-evoked CGRP release. AcPep alone at a concentration of $10 \mu \mathrm{M}$ does not induce CGRP release; however, AcPep significantly enhances both capsaicin and $\mathrm{KCl}$-evoked CGRP release in primary DRG neuronal cultures. Capsaicin evoked a dosedependent increase in CGRP release, which is bell-shaped with maximum enhancement occurring at $10 \mathrm{~nm}$ capsaicin. This observation is in agreement with an earlier finding by Wardle et al. (1997) in which capsaicin evoked a bell-shaped, concentrationdependent CGRP release from the central terminals of the afferent nerves in the spinal cord.

Steinhoff et al. (2000) have demonstrated previously that sub- 
CoPep

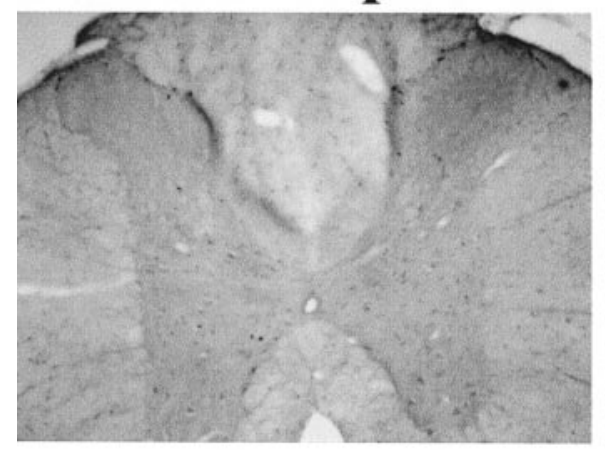

\section{CoPep-CAP}

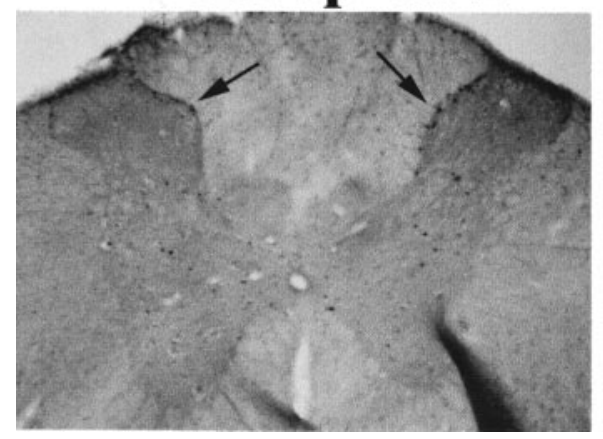

AcPep

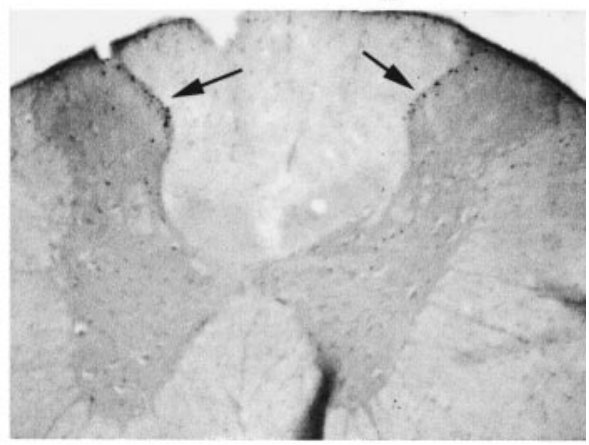

AcPep-CAP

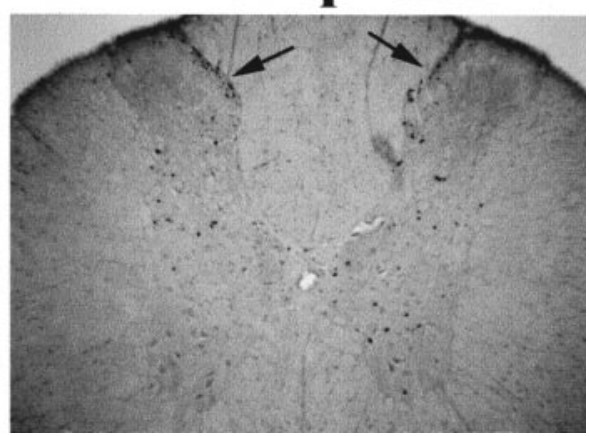
tographs of spinal cord sections (T10) for each treatment group shown in Figure 5, stained for Fos. Magnification, $4 \times$. CoPep, $100 \mu \mathrm{M}$ control peptide; AcPep, $100 \mu \mathrm{M}$ activating peptide; CoPep-CAPS, $100 \mu \mathrm{M}$ control peptide, followed by $0.5 \mathrm{mg} / \mathrm{kg}$ capsaicin; AcPep-CAPS, $100 \mu \mathrm{M}$ activating peptide, followed by $0.5 \mathrm{mg} / \mathrm{kg}$ capsaicin. The arrow refers to representative Fos immunoreactivity. Inf usion of AcPep alone into the pancreatic duct produced more Fos-IR neurons in segments T9 and T10 compared with CoPep. When infusion of AcPep or CoPep was followed by infusion of capsaicin, even more Fos was observed after pretreatments with AcPep.

cutaneous injection of AcPep into the rat paw results in the release of CGRP and substance $P$ from peripheral afferent nerve endings in vivo and from slices of spinal cord in vitro. Our in vitro data suggesting that adult rat DRG neurons can be sensitized through a PAR-2-specific mechanism. We therefore postulated that such sensitization in vivo will lead to enhanced release of these or other neurotransmitters centrally, with consequently greater activation of second-order neurons in the dorsal horn. Intraductal injection of $10 \mu \mathrm{M}$ AcPep significantly increased the Fos expression in spinal segments, T9 andT10, when compared with injection of CoPep. No difference in Fos expression was detected between left and right hemisections for each individual segment, in keeping with the midline location of the pancreas. The injection of AcPep plus capsaicin increased Fos expression even greater when compared with CoPep plus capsaicin or AcPep alone. Most Fos-IR nuclei were observed in region A. This region includes laminas I and II that contain primarily nociceptive primary nerve terminals. Interestingly, the enhanced Fos expression after injection of AcPep plus capsaicin but not with AcPep alone can also be observed in regions B $(0.1,0.3$, and $0.5 \mathrm{mg} / \mathrm{kg}$ capsaicin but not with $0.7 \mathrm{mg} / \mathrm{kg}$ capsaicin) and $\mathrm{C}(0.1$ and 0.3 capsaicin $\mathrm{mg} / \mathrm{kg}$ ). Region B includes laminas III, IV, and V. Lamina $\mathrm{V}$, the neck of the dorsal horn, receives input from visceral afferent (nociceptive) neurons. Nociceptive neurons have also been identified in the ventral horn (region C), particularly in laminas VII and VIII and around the central canal (lamina X). Although these do not directly communicate with primary nociceptive nerve terminals, they may be activated by other neurons, including those from laminas I and II (Presley et al., 1990). Our data therefore stress the importance of nociceptive neurons in the superficial dorsal horn (region A) but also indicate that other neurons (region B) and even some of the ventral neurons (region C) may play a role in the processing of noxious stimuli from the rat pancreas.
The difference in Fos expression could not be attributed to a difference in the histology of the individual treatment groups. These observations suggest that pancreatic sensory neurons can mediate nociception through a PAR-2-mediated mechanism that is independent of the presence of inflammation. Unlike injection into the rat paw (Steinhoff et al., 2000), injection of AcPep into the pancreatic duct did not cause significant inflammation within the short $(2.5 \mathrm{hr})$ time frame of our study.

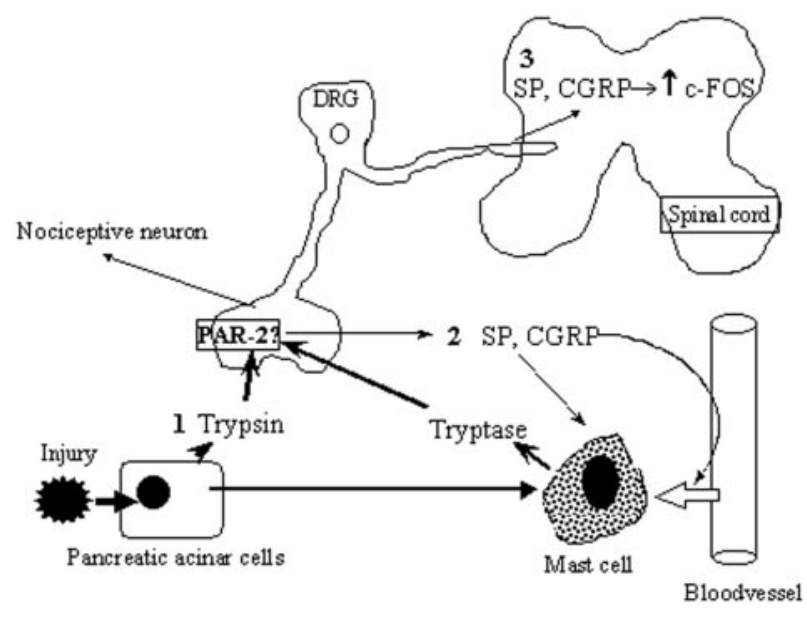

Figure 7. Proposed involvement of PAR-2 in nociceptive signaling in pancreatitis. 1, In pancreatitis, PAR-2 receptors on sensory neurons are activated by proteases released from injured pancreatic epithelial cells. Degranulation of mast cells releases tryptase, which also acts on PAR-2 receptors. 2, PAR-2-stimulated release of CGRP and SP occurs peripherally, which further amplifies inflammation and mast cell degranulation. 3 , Central release of these neurotransmitters leads to activation of nociceptive pathways and an increase in Fos expression. Peripheral sensitization of the VR-1 receptor may also occur, perhaps mediated by PAR-2induced increases in intracellular calcium. 
AcPep treatment by itself increased Fos expression in thoracic spinal cord neurons compared with controls, in accordance with experiments by Steinhoff et al. (2000) showing AcPep-induced increases in CGRP release from spinal cord sections and AcPepinduced increases in plasma extravasation. In contrast, AcPep by itself had no apparent effect on basal CGRP release from cultured DRG neurons; this apparent discrepancy may be a result of the culture conditions in which dissociated neurons, consisting mainly of cell bodies, are used.

Short-term sensitization of nociceptors can result from immediate post-translational changes in ion channels or receptors induced by various components of the inflammatory soup, including ions $\left(\mathrm{K}^{+}\right.$and $\left.\mathrm{H}+\right)$, amines (5-HT and histamine), kinins (bradykinin), prostanoids [prostaglandin E2 (PGE2)], purines (ATP), cytokines (TNF $\alpha$, interleukin-1, and interleukin-6), nitric oxide, and caloric activity (heat). These agents, acting via specific receptors and/or cellular messengers, initiate a chain of events that lead to increases in the phosphorylated state of critical ion channels (Gold, 1999; Porreca et al., 1999). Based on the enhanced response to capsaicin, both in vitro and in vivo, it is tempting to suggest a functional coupling between the PAR-2 and the vanilloid receptor VR-1. VR-1 is capable of rapid sensitization, as illustrated by the progressive augmentation of current through the VR-1 ion channel in response to repeated applications of thermal or acidic stimulation (Caterina et al., 1997; Tominaga et al., 1998). In several systems, PAR-2 generally couples with phospholipase $\mathrm{C} \beta$ with subsequent formation of inositol phosphate and mobilization of intracellular calcium stores (Déry et al., 1998). The increased intracellular calcium levels induced by activation of the PAR-2 receptor may result in sensitization of the VR1 receptor in nociceptor neurons (Fig. 6). However, other effects may also be important in this context, including PAR-2induced production of PGE2 as has been shown in other systems, including both the intestine and airway (Cocks et al., 1999).

Studies on the role of the PAR-2 system in somatic nociception are just beginning to emerge in the literature. Kawabata et al. (2001) showed that injection of AcPep into the rat paw can lower the threshold for thermal nociception. Most recently, Vergnolle et al. (2001) demonstrated that the injection of subinflammatory doses of AcPep into the paw of mice can induce both thermal and mechanical hyperalgesia. This response is completely abolished in neurokinin-1 (NK-1)- and preprotachykinin-A-deficient mice and significantly reduced in PAR-2-deficient mice, suggesting a role for PAR-2 in NK-1 mediated somatic nociceptive signaling. Our study suggests a new role of PAR-2 as an important mediator in visceral nociceptive signaling and provides evidence for a novel potential link between inflammation and pain in the pancreas. Although AcPep increased Fos expression in pancreatic-specific spinal cord segments, the effects of the naturally occurring PAR-2 agonists such as trypsin and tryptase on Fos expression has yet to be determined. However, because these naturally occurring agonists are released in pancreatitis, our results suggest that they may not only cause additional tissue damage and perpetuate inflammation but also contribute to the development of pain by direct effects on nociceptors located on pancreatic afferent neurons (Fig. 7).

In conclusion, our data demonstrate PAR-2-mediated sensitization of primary afferent neurons in vitro and in vivo and therefore support a novel role for PAR-2 in visceral nociceptive signaling.

\section{REFERENCES}

Al-Ani B, Saifeddine M, Kawabata A, Renaux B, Mokashi S, Hollenberg MD (1999) Proteinase-activated receptor 2 (PAR2): development of a ligand-binding assay correlating with activation of PAR-2 by PAR-1 and PAR-2-derived peptide ligands. J Pharmacol Exp Ther 290:753-760.

Caterina MJ, Schumacher MA, Tominaga M, Rosen TA, Levine JD, Julius D (1997) The capsaicin receptor: a heat-activated ion channel in the pain pathway. Nature 389:816-824.

Chapman V, Besson JM (1997) Pharmacological studies of nociceptive systems using the c-FOS immunohistochemical technique: an indicator of noxiously activated spinal neurons. In: The Pharmacology of pain, Handbook of experimental pharmacology, pp 130, 235-279. Berlin: Springer.

Cocks TM, Moffat JD (2000) Protease-activated receptors: sentries for inflammation? Trends Pharmacol Sci 21:103-108.

Cocks TM, Fong B, Chow JM, Anderson GP, Frauman AG, Goldie RG, Henry PJ, Carr MJ, Hamilton JR, Moffatt JD (1999) A protective role for protease-activated receptors in airways. Nature 398:156-160.

Delree P, Leprince P, Schoenen J, Moonen G (1989) Purification and culture of adult rat dorsal root ganglia neurons. J Neurosci Res 23:198-206

Déry O, Corvera CU, Steinhoff M, Bunnett NW (1998) Proteinaseactivated receptors: novel mechanisms of signaling by serine proteases. Am J Physiol 274:C1429-C1452.

Dray A (1995) Inflammatory mediators of pain. $\mathrm{Br} \mathrm{J}$ Anaesth 751:125-131.

Gold MS (1999) Tetrodotoxin-resistant $\mathrm{Na}^{+}$currents and inflammatory hyperalgesia. Proc Natl Acad Sci USA 96:7645-7649.

Hebel R (1976) Anatomy of the laboratory rat. In: Anatomy of the laboratory rat (Hebel R, Stromberg MW, ed), pp 120. Baltimore: Williams \& Wilkins.

Hingtgen CM, Waite KJ, Vasko MR (1995) Prostaglandins facilitate peptide release from rat sensory neurons by activating the adenosine 3',5'-cyclic monophosphate transduction cascade. J Neurosci 15:5411-5419.

Hofbauer B, Saluja AK, Lerch MM, Bhagat L, Bhatia M, Lee HS, Frossard JL, Adler G, Steer ML (1998) Intra-acinar cell activation of trypsinogen during caerulein-induced pancreatitis in rats. Am J Physiol 275:G352-G362.

Hollenberg MD, Saifeddine M, Al-Ani B, Kawabata A (1997) Proteinase-activated receptors: structural requirements for activity, and receptor selectivity of receptor-activating peptides. Can J Physiol Pharmacol 75:832-841.

Hunt SP, Pini A, Evan G (1987) Induction of c-FOS like protein in spinal cord neurons following sensory stimulation. Nature 328:632-634.

Ishihara H, Connolly AJ, Zeng D, Kahn ML, Zheng YW, Tommons C, Tram T, Coughlin SR (1997) Protease-activated receptor 3 is a second thrombin receptor in humans. Nature 386:502-506.

Kahn ML, Zheng YW, Huang W, Bigornia V, Zen D, Moff S, Farese JRRV, Tam C, Coughlin SR (1998) A dual thrombin receptor system for platelet activation. Nature 394:690-694.

Kawabata A, Kawao N, Kuroda R, Tanaka A, Itoh H, Nishikawa H (2001) Peripheral PAR-2 triggers thermal hyperalgesia and nociceptive responses in rats. NeuroReport 12:715-719.

Kim KH, Lee MG, Kim DG (1996) The cholecystokinin receptor antagonist L-364, 718 reduces taurocholate-induced pancreatitis in rats. Int J Pancreatol 20:205-211.

Molander C, Xu Q, Grant G (1984) The cytoarchitectonic organization of the spinal cord in the rat. I. The lower thoracic and lumbosacral cord. J Comp Neurol 230:133-141.

Nguyen TD, Moody MW, Steinhoff M, Okolo C, Koh DS, Bunnett NW (1999) Trypsin activates pancreatic duct epithelial cell ion channels through proteinase-activated receptor-2. J Clin Inv 103:261-269.

Nystedt S, Emilsson K, Wahlestedt C, Sundelin J (1994) Molecular cloning of a potential proteinase activated receptor. Proc Natl Acad Sci USA 91:9208-9212.

Nystedt S, Emilsson K, Larsson AK, Strömbeck B, Sundelin J (1995) Molecular cloning and functional expression of the gene encoding the human proteinase-activated receptor 2. Eur J Biochem 232:84-89.

Nystedt S, Ramakrishnan V, Sundelin J (1996) The proteinase-activated receptor is induced by inflammatory mediators in human endothelial cells. J Biol Chem 271:14910-14915.

Porreca F, Lai J, Bian D, Wegert S, Ossipov MH, Eglen RM, Kassotakis L, Novakovic S, Rabert DK, Sangameswaran L, Hunter JC (1999) A comparison of the potential role of the tetrodotoxin-insensitive sodium channels, PN3/SNS and NaN/SNS2, in rat models of chronic pain. Proc Natl Acad Sci USA 96:7640-7644.

Presley RW, Menetrey D, Levine JD, Basbaum AI (1990) Systemic morphine suppresses noxious stimulus-evoked Fos protein-like immunoreactivity in the rat spinal cord. J Neurosci 10:323-335.

Steinhoff M, Vergnolle SH, Young SH, Tognetto M, Amadesi S, Ennes HS, Trevisani M, Hollenberg MD, Wallace JL, Caughey GH, Mitchell SE, Williams LM, Geppetti P, Mayer EA, Bunnett NW (2000) Ago- 
nists of proteinase-activated receptor 2 induce inflammation by a neurogenic mechanism. Nat Med 6:151-158.

Tito J, Rudnicki M, Jones DH, Alpern HD, Gold MS (1993) Peptide YY ameliorates cerulein-induced pancreatic injury in the rat. Am J Surg 165:690-696.

Tominaga M, Caterina MJ, Malmberg AB, Rosen TA, Gilbert H, Skinner K, Raumann BE, Basbaum AI, Julius D (1998) The cloned capsaicin receptor integrates multiple pain-producing stimuli. Neuron 21:531-543.

Vergnolle N, Bunnett NW, Sharkey KA, Brussee V, Compton SJ, Grady EF, Cirino G, Gerard N, Basbaum AI, Andrade-Gordon P, Hollenberg MD, Wallace JL (2001) Proteinase-activated receptor-2 and hyperalgesia: a novel pain pathway. Nat Med 7:821-826.

Vu TK, Hung DT, Wheaton VI, Coughlin SR (1991) Molecular cloning of a functional thrombin receptor reveals a novel proteolytic mechanism of receptor activation. Cell 64:1057-1068.
Wardle KA, Ranson J, Sanger GJ (1997) Pharmacological characterization of the vanilloid receptor in the rat dorsal spinal cord. Br J Pharmacol 121:1012-1016.

Winston J, Toma H, Shenoy M, Pasricha PJ (2001) Nerve growth factor regulates VR-1 mRNA levels in cultures of adult dorsal root ganglion neurons. Pain 89:181-186.

Won MH, Park HS, Jeong YG, Park HJ (1998) Afferent innervation of the rat pancreas: retrograde tracing and immunohistochemistry in the dorsal root ganglia. Pancreas 16:80-87.

$\mathrm{Xu} \mathrm{W}$, Andersen H, Whitmore TE, Presnell SR, Yee DP, Ching A, Gilbert T, Davie EW, Foster DC (1998) Cloning and characterization of human protease-activated receptor 4. Proc Natl Acad Sci USA 95:6642-6646.

Young SH, Ennes HS, Steinhoff M, Mayer EA, Bunnett NW (2000) Rat dorsal root ganglia (DRG) neurons express proteinase activated receptors (PARS) 1 and 2. Gastroenterology 118:A2013. 